\title{
Long Term Inter- And Intra-Regional Stochastic Trends To Middle East And North African Capital Markets
}

Eric Girard (E-mail: mfgirard@befac.indstate.edu), Indiana State University Eurico J. Ferreira (E-mail: mfpref@befac.indstate.edu), Indiana State University

\begin{abstract}
This paper investigates the contribution of Middle East and North African (MENA) capital markets to global strategic asset allocation. Eleven MENA stock markets are examined from January $1^{\text {st }}$, 1990 to December 30th, 2001. Cointegration studies are conducted on daily, weekly and monthly stock market index price to investigate long-term market linkages. Our results indicate few pairwise stochastic trends between markets, but no common long-term co-movements. We suggest that MENA markets provide diversification potentials for the global investor and should not be treated as a block for global strategic asset allocation purposes.
\end{abstract}

\section{Introduction}

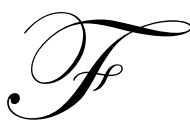

inancial integration among major world capital markets has been widely addressed in the literature. Indeed, integration is a major concern to investors and firms since it diminishes the diversification potentials for global portfolio investors. Also, the cost of capital for a local firm in a segmented market is likely to be much higher than for a multinational corporation that has access to international capital markets. Recently, studies have shown that emerging markets provide opportunities to enhance the performance of global portfolios. For instance, Bekaert and Harvey (1997) show that emerging capital markets provide high and predictable returns uncorrelated with other major developed markets.

Wars, political turmoil, economic instability and institutional underdevelopment have traditionally been powerful obstacles to an increased access to Middle-Eastern and North African region (MENA) capital markets. However, MENA countries' financial integration has become a long term goal which is progressively tackled in terms of intra-regional agreements like the Gulf Cooperation Council (GCC) consisting of oil producing Gulf countries. Outside the closed circle of GCC countries, Egypt, Morocco, Jordan and Turkey have progressively open their capital markets to all MENA investors. Furthermore, capital markets in these four countries have recently witnessed significant economic and financial development geared towards an increase in their openness to foreign investors.

Very few articles on MENA capital markets integration have been published and, often, their findings are inconsistent. Abraham, Seyyed and Al-Elg (2001), in an overview of the stock markets in Bahrain, Kuwait and Saudi Arabia, conclude that the three markets are suitable for international diversification purposes, and also can be used to hedge against oil price fluctuations. They use monthly index returns from 1993 to 1998, which equals to 65 data points, and observe low or negative correlations between markets. The authors argue that their findings underline the potential MENA capital markets offer for risk reduction. Omran and Gunduz (2001) use a multivariate cointegration methodology and find no long term stochastic trends between Jordan, Turkey, Egypt, Israel and Morocco. The authors use 37 monthly observations, from January 1996 to June 1999, and also conclude that MENA capital markets offer diversification incentive to the global investor. Darrat, Elkhal and Hakim (2000) use 35 monthly observations, from October 1996 to August 1999 and find long-term bivariate cointegrative relationships for Morocco-Egypt and Morocco-Jordan, but no multivariate cointegrative relationships between the three capital markets. The authors investigate pairwise long term stochastic trends with the US market and find none. They 
conclude that the three markets, as a block, offer diversification potentials for the global investor. A study by Neaime (2002) suggests that GCC markets are segmented and provide diversification potentials. However, the author shows that Morocco, Egypt, Turkey and Jordan are integrated with the world financial markets.

The purpose of this paper is two-fold: Firstly, we investigate whether the liberalization efforts instilled in the region have started crystallizing and triggered financial integration. This is an important issue because increased liberalization within the MENA region will attract investments to the region, which will improve and enhance market growth and liquidity, and reduce the costs of raising capital in the local market. Secondly, we examine whether MENA capital markets should be treated as a block in a globally diversified strategic portfolio. If MENA markets are segmented, an argument for international diversification exists in that each MENA capital market can be considered as a "stand-alone" asset class in a globally diversified portfolio.

Previous studies have only used small samples of few MENA capital markets to conclude on the inexistence of intra-regional long-term price linkages. The paper contributes to the literature by applying extensive testing to a larger sample of countries. Furthermore, the paper addresses two conceptual questions yet unanswered: (1) Are there intra-regional linkages with other MENA markets not included in previous studies? (2) Are there any inter-regional linkages between MENA capital markets and other regional blocks? We intend to fill this void in the literature by investigating long-run linkage between eleven MENA capital markets and five regional indices.

The results of our study for the equity markets in Bahrain, Egypt, Israel, Jordan, Kuwait, Lebanon, Morocco, Oman, Saudi Arabia and Turkey indicate that at least one significant relationship exists for the following pairs: Bahrain-Jordan, Israel-Turkey, Morocco-Saudi Arabia; Morocco-Tunisia. Evaluation of inter-regional linkages for those equity markets with five regional Morgan Stanley Capital International indices, determined for Asia, Europe, East Europe, Latin America and North America, suggests the following significant pairwise relationships: Israel-North America, Morocco-North America, Saudi-Arabia-North America, Tunisia-North America, Tunisia-North America, Kuwait-East Europe, and Tunisia-Europe. Our findings also indicate that as a block MENA capital markets do not exhibit common stochastic trends between each other, nor with the regional market indices used in this study. Diversification potentials are also detected when MENA markets are considered for global strategic allocation.

The remainder of this paper is organized as follows. In section 2, the data and methodology are described. In section 3, analysis and interpretations of the empirical findings are provided. A conclusion is presented in Section 4.

\section{Data And Methodology}

\subsection{Sample Selection}

Market indices are obtained from Datastream. There are several possible sources for MENA market returns: Morgan Stanley Capital International (MSCI), International Finance Corporation (IFC) and local indices. Each of these sources started to cover MENA markets at different dates. We choose the provider that started the coverage the earliest. For instance, Jordan and Turkey were covered by MSCI in the late 80s. Egypt, Israel, and Morocco are also covered the earliest by MSCI during the 90s. Saudi Arabia, Bahrain and Oman ${ }^{1}$ are only covered by IFC. Kuwait, Lebanon and Tunisia ${ }^{2}$ price series are only available in local indices, which coverage started in the 90s. For the regional indices, we use MSCI AC Asia, MSCI AC Europe, MSCI AC East Europe, MSCI AC Latin America, and MSCI AC North America. We use regional indices rather than country indices for several reasons: Firstly, it would be difficult to justify the choice of one country versus another within a region; furthermore, it is impossible to perform the analysis with all countries in each region. Secondly, we try to address the issue of

\footnotetext{
1 Oman MUSCAT (local index) is available since the mid-90s. However, when plotting the return series from 1995 to 2001, we observed inconsistency in the series in 1998 and 1999. Subsequently, we use the price series from the IFC database.

2 IFC has started to cover Tunisia as a "frontier market" in a monthly frequency since the end of 1995 . We found that the local series "TUNINDEX" (available in a daily frequency) has a correlation of 0.91 with IFCM-Tunisia from 1998:01 to 2001:06.
} 
integration in the mindset of a global investor, who is likely to implement a global strategic asset allocation by allocating across regional blocks rather than specific markets.

We use daily, weekly and monthly market index data for observation periods within the January 1990 through December 2001 range. We chose a starting date of January $1^{\text {st }}, 1990$ because nine of the eleven MENA price series are only available after 1990. The observation periods for all countries are not the same, but the construction of the indices is based on value-weighted portfolios. MSCI and IFC country indices are usually highly correlated providing consistency to our tests across markets; they capture the spirit of an all-share index by including replicable subsets of shares and targeting sixty percent of total market capitalization. These indices do not take into consideration restrictions on foreign ownership. A summary of the source, starting date and observations for each series is provided in Table 1.

All prices are in US Dollar. This is more appropriate in segmented markets because inflation trends are taken into account through Fisher equation (Liew, 1995). Also, it provides uniformity in the comparison of one market to another. When we use local series (Kuwait, Lebanon and Tunisia), prices are converted in Dollars using the exchange rate series provided by Datastream.

\subsection{Methodology}

Linkages among equity markets are important components for country selection within a global asset allocation. International equity linkages and benefits from diversification are known to be inversely related. Also, capital markets are in long-term equilibrium when long-term expectations in one market can be used to predict longterm movements in another market. This association is known as cointegration.

Since we examine if there is a benefit to allocate strategically among the MENA capital markets, the methodology is geared towards testing the existence of cointegration. As indicated previously, MENA markets data coverage does not start at same time. Therefore, bivariate cointegration tests are performed paiwise and the number of observations used in the test corresponds to those in the more recent of the two series.

We investigate regional stock market integration using stock index price levels for all eleven countries and five regional indices. Following Arshanapalli and Doukas (1993) and Granger, Huang and Yang (2000), we conduct bilateral Johansen (1988) cointegration tests to determine if a long-term relationship exists between the markets ${ }^{3}$. Testing for cointegration is undertaken once it is found that each series contains one unit root. ${ }^{4}$

That is, for all pairs, we evaluate whether $\varepsilon_{t}$ in the cointegrating regression $x_{t}=\lambda_{0} y_{t}+\sum_{i=1}^{k-1} \theta_{i} \Delta x_{t-i}+\varepsilon_{t}$ is found to be $\mathrm{I}(0)$ given any particular cointegrating rank, subject to the following five cointegrating equations nested from the most restrictive to the least restrictive:

- $\quad$ Case a: no trend nor intercept in the cointegration regression and cointegrating equation-i.e., $\Delta \varepsilon_{t}=\rho \varepsilon_{t-1}+e_{t}$ with Ho: $\rho=1$

- $\quad$ Case b: intercept in the cointegration regression-i.e., $\Delta \varepsilon_{t}=\rho\left(\varepsilon_{t-1}+\lambda_{1}\right)+e_{t}$ with Ho: $\rho=1$

- Case c: intercept in the cointegration regression and cointegrating equation-i.e., $\Delta \varepsilon_{t}=\rho\left(\varepsilon_{t-1}+\lambda_{1}\right)+\lambda_{2}+e_{t}$ with Ho: $\rho=1$

- $\quad$ Case d: intercept and trend in the cointegration regression and intercept in the cointegrating equation-i.e., $\Delta \varepsilon_{t}=\rho\left(\varepsilon_{t-1}+\lambda_{1} t+\lambda_{3}\right)+\lambda_{2}+e_{t}$ with Ho: $\rho=1$

- $\quad$ Case e: intercept and trend in the cointegration regression and cointegrating equation-i.e., $\Delta \varepsilon_{t}=\rho\left(\varepsilon_{t-1}+\lambda_{1} t+\lambda_{3}\right)+\lambda_{2} t+\lambda_{4}+e_{t}$ with Ho: $\rho=1$

3 In the cointegration theory (Engle and Granger, 1987), if non-stationary variables do not drift apart from each other, there is a long-term linkage between those variables; it is often seen as a test of cross-border equity market efficiency.

4 Both Augmented Dickey-Fuller (ADF) and Kwiatkowski, Phillips, Schmidt and Shin (KPSS) tests are conducted to test whether all series are integrated of order one. 
Lags and cases are established using the Akaike Info Criterion (AIC), Schwartz Info Criterion (SIC) and Baysian Info Criterion ${ }^{5}$ (BIC). Likelihood ratio is used as a trace statistic to determine the number of cointegration equations between the two non-stationary variables; significance is set by the critical values reported in OsterwaldLenum (1992). Broadly speaking, cointegration analysis provides insights about the benefits of portfolio diversification and strategic asset allocation in this region of the world.

\section{Results}

Tables 2 and 3 list the results of the Augmented Dickey Fuller and Kwiatkowski, Phillips, Schmidt and Shin $^{6}$ tests for unit root in the level of each of the 16 index price series. Values for which we fail to reject the null hypothesis at least at the 5\% level are highlighted on both tables. As a result, all results reported on Table 2 indicate that a trend stationary is rejected for the series for daily, weekly, and monthly frequencies. The ADF test result in Table 2 for a four-lag of the monthly series, for instance, indicates a statistic value of -0.411 for Egypt (EG), when the critical values at the 1,5 , and 10 percent levels of significance are $-2.59,-1.95$, and -1.62 , respectively. This result, of course, would lead us to reject a trend stationary for the series. The KPSS tests (Table 3) fail to reject stationarity for monthly frequencies in eight of the sixteen series tested. On the other hand, the KPSS test results (Table 3) yields a statistic value of 0.439 for the same country and a four-month lag. Comparing this statistic to the critical values of $0.739,0.463$, and 0.347 , respectively, for levels of significance at the 1,5 , and 10 percent, lead us to accept the null hypothesis of a trend stationary for the series. Such conflicting test results prevent us from rejecting a trend stationary for that country monthly series, as well for seven other countries.

In sum, results of Tables 2 and 3 allow us to conclude that level series are integrated of order-one for daily and weekly data. For monthly data, the results are puzzling and evidence an interesting situation in which KPSS tests contradict ADF tests results. Moreover, these findings suggest that the results of Darrat, Elkhal and Hakim (2000) based on series of 36 monthly observations need to be reexamined-i.e., cointegration analysis with monthly data among those markets may generate spurious cointegrative relationships.

Table 4 provides the bivariate Johansen cointegration test results. As in Engle and Granger (1987), we assess whether a linear combination of two non-stationary series might be stationary. If such a stationary linear combination exists, it indicates that a long-run equilibrium relationship exists among the variables. Lags and cointegration equations are chosen based on the Akaike Info Criterion. LR statistics are reported with critical values tabulated by Osterwald-Lenum (1992).

Tables 4 and 5 report the results of 110 bivariate cointegration analysis in daily, weekly and monthly frequencies. Because we were not sure of whether cointegration existed due to infrequent trading or the lack of nonstationarity in one of the variables, we used a conservative approach by concluding on long-term stochastic trends if they could be observed in all frequencies. The consensus of optimal lag/case was typically found with the AIC. However, in some cases we used the SIC because AIC failed to converge to a minimum. In rare cases (for series in weekly and monthly frequencies), we failed to find convergence with either the AIC, SIC and BIC. In such cases, we report "NC" (no convergence).

Significant results were found for eight intra-regional, as highlighted on Table 4, and eight inter-regional, as highlighted on Table 5, bilateral cointegration equations out of 110 possible relationships. For instance, Table 4 results show at least one significant cointegration relationship for daily, weekly, and monthly frequencies for the following 8 pairs: Bahrain-Jordan (21.30, 20.21, and NC, respectively for daily, weekly, and monthly frequencies); Egypt-Turkey (13.87); Israel-Jordan (25.92, and 30.21); Israel-Turkey (30.73, 16.69, and 22.28); Kuwait-Morocco (18.20, and 18.91); Lebanon-Morocco (16.32, and 12.64); Morocco-Saudi Arabia (26.98, 26.15, NC); and MoroccoTunisia $(25.35,27.35$, and NC). Table 5 results indicate at least one significant cointegration relationship for the

\footnotetext{
5 We evaluate model selection criteria in terms of consistency. As we cannot know the true data generating process, the most as ymptotically efficient model selection criterion is the Akaike Info Criterion. If the AIC cannot be minimized, we turned to the SIC and the BIC, respectively.

6 Since ADF tends to be biased not to reject the null hypothesis of non-stationarity, in particular for small samples, more restrictive KPSS tests for the null hypothesis of trend stationarity are used to complement our analysis.
} 
following 8 pairs: Israel-North America (20.42, 23.43, and 24.62, respectively for daily, weekly, and monthly frequencies); Jordan-Asia (12.81, and 12.91); Kuwait-East Europe (16.85, 16.13, and 12.98); Morocco-East Europe (26.43, and 20.38); Morocco-North America (20.85, 20.36, and 25.98); Saudi-Arabia-North America (21.94, 20.62, and NC); Tunisia-Europe (18.65, 24.31, and NC); and Tunisia-North America (12.93, 18.66, and NC);.

It is worth noticing that for the 55 [= (11 x 10) / 2] possible pair combinations between countries in Table 4 , only eight exhibit significant cointegration relationships. As for the 55 possible inter-regional pair combinations of Table 5, only eight pairs show significant cointegration relationships for their three frequency series. Thus, in the light of these findings we conclude that MENA capital markets, as a block, do not have common stochastic trends between each other, nor with other regional indices. Except perhaps for Israel, Morocco, Saudi Arabia and Tunisia, MENA markets provide long term diversification incentives for North American investors' (Canadian and US) global strategic allocation.

It is true that the access to GCC capital markets has long been restricted to GCC investors. Yet, mutual funds shares in these markets (Bahrain, Kuwait, Oman, and Saudi Arabia) are available to foreign investors. For the other markets (Egypt, Israel, Jordan, Lebanon, Morocco, and Turkey), the access is currently either unrestricted or limited to up to 50 percent ownership of a company's capital. Furthermore, repatriation of capital and dividends are allowed. Accordingly, we show in Figure 1 the risk-return tradeoff examples using 1990-2001 data to confirm potential benefits of global strategic allocations with MENA capital markets. It is shown what happens when we combine, first, just all regional blocks (Asia, Europe, East Europe, Latin America, and North America), second, all regional blocks with MENA countries, as a block (when we build an equally-weighted index for that matter), and, third all regional blocks with individual MENA countries. We report the composition of three portfolios (A, C and D) obtained from minimizing the Value-at-Risk (VaR), i.e., the worst expected loss under normal market conditions, and two other portfolios (B and E) that are optimized by maximizing the Sharpe ratio. Portfolio A (29.9 percent Morocco, 18.9 percent Saudi Arabia, 1.1 percent Turkey, 5.7 percent Tunisia, 4.9 percent Europe, 7.2 percent Latin America, and 27.3 percent North America) would have been a better choice for low-risk tolerance allocation strategies than any other portfolio, such as C (21.8 percent Europe, 13.8 percent Latin America, 56.8 percent North America, and 7.6 percent MENA) that treats MENA markets as a block or even D (24.8 percent Europe, 14.7 percent Latin America, and 60.5 percent North America) that does not include MENA markets. Furthermore, Portfolio $\mathrm{C}$ would have been a better choice for low-risk tolerance global allocation strategies than portfolio D, which indicates that a MENA block provides diversification potential in a global regional allocation strategy.

Over the same period, portfolios on the efficient frontier of A, such as B (24.4 percent Morocco, 12.3 percent Saudi Arabia, 3.1 percent Turkey, 18 percent Latin America, and 42.2 percent North America) which includes MENA countries as separate asset would have been a better selection than portfolio E (29.8 percent Latin America and 70.2 percent Latin America), for example, which do not include MENA markets. For risk levels that are higher than about 17 percent, though, there would not have been material advantage in selecting portfolios on the A-B efficient frontier vis-à-vis those on the D-E efficient frontier. Since portfolios on this latter frontier include no MENA markets in their composition, global regional allocation strategies that would have targeted risk-return levels on the upper tail of the efficient frontier, could have been achieved with or without investments in those emerging markets. This result also supports the notion that the major incentive to include MENA countries in global asset allocation strategies comes from the low correlations between the investments returns in those capital markets. Once they are combined the benefits of diversification are amplified. 
Figure 1

Evidence Of The Diversification Potentials

From Using MENA Capital Markets As Stand-Alone Asset Classes:

Efficient Frontiers Of All Regional Blocks And MENA Countries,

All Regional Blocks And MENA Index, And All Regional Blocks

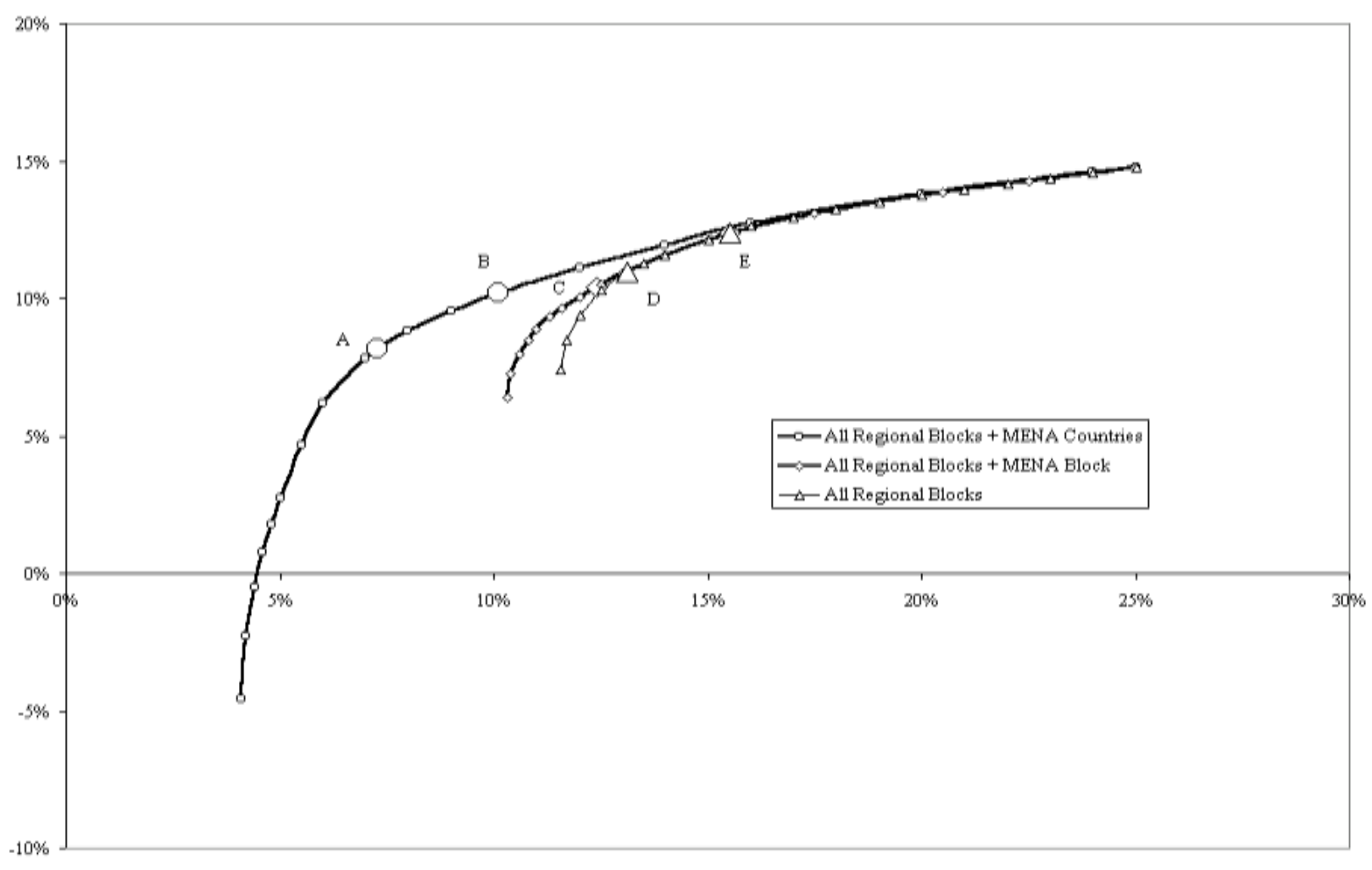

To find the composition of portfolios A, B, C, D and E, we optimize:

$$
\max _{\omega} \frac{\Gamma^{\mathrm{T}} \mathrm{R}-\mathrm{C}}{\Gamma^{\mathrm{T}} \mathrm{S} \Gamma}
$$

where $\Gamma^{\mathrm{T}}=\left[\begin{array}{lll}\omega_{1} & \ldots & \omega_{\mathrm{n}}\end{array}\right], \quad \mathrm{R}=\left[\begin{array}{c}\mathrm{r}_{1} \\ \ldots \\ \mathrm{r}_{\mathrm{n}}\end{array}\right]$, and $\mathrm{S}=\left[\begin{array}{ccc}\sigma_{1,1} & \ldots & \sigma_{1, \mathrm{n}} \\ \ldots & \ldots & \ldots \\ \sigma_{\mathrm{n}, 1} & \ldots & \sigma_{\mathrm{n}, \mathrm{n}}\end{array}\right]$,

$\omega_{i}$ is the proportion invested in asset $i, r_{i}$ is the realized return on asset $i$, and $\sigma_{i, j}$ is the covariance between the returns of asset $i$ and asset $\mathrm{j}, \mathrm{C}$ is a constant that takes the value of (1) zero for the minimum Value at Risk (portfolios A, D and C) and (2) the risk free rate (T-bill rate) for the maximum Sharpe ratio (portfolios B and E). Portfolio A has an allocation of 29.9 percent in Morocco, 18.9 percent in Saudi Arabia, 1.1 percent in Turkey, 5.7 percent in Tunisia, 4.9 percent in Europe, 7.2 percent in Latin America, and 27.3 percent in North America. Portfolio B has the following weights: 24.4 percent in Morocco, 12.3 percent in Saudi Arabia, 3.1 percent in Turkey, 18 percent in Latin America, and 42.2 percent in North America. Portfolio C allocates 21.8 percent in Europe, 13.8 percent in Latin America, 56.8 percent in North America, and 7.6 percent in MENA. Portfolio D has 24.8 percent in Europe, 14.7 percent in Latin America, and 60.5 percent in North America. Portfolio E allocates 29.8 percent in Latin America and 70.2 percent North America. 


\section{Conclusion}

Using price levels, we find evidence of a relative high degree of segmentation between MENA markets. Cointegration tests reveal some pairwise but no common stochastic trends to all MENA markets-i.e., no long-run co-movements. We find that Israel and Turkey are more integrated; they seem to process information flows from global markets and act as conduits to other, smaller, MENA markets. Apart from Israel and Turkey, we find little evidence of inter and intra-regional linkages in MENA capital markets. To the best of our knowledge, this result is also interesting since it has not been reported for other emerging markets. Risk-return tradeoff examples also suggest that strategically allocated portfolios across MENA markets could have been beneficial over 1990-2001. In fact, such strategies seem to benefit rather diversification than high risk-return objectives.

\section{References}

1. Abraham Abraham, Fazal J Seyyed, and Ali Al-Elg. "Analysis of Diversification Benefits of Investing in the Emerging Gulf Equity Markets." Managerial Finance, 27 (2001), 47-57.

2. Arshanapalli, B. and J. Doukas. "International Stock Market Linkages: Evidence from the Pre-And PostOctober 1987 Period." Journal of Banking and Finance 17 (1993), 193-208.

3. Bollerslev, Tim, and J. Wooldridge. "Quasi-Maximum Likelihood Estimation and Inference in Dynamic Models with Time Varying Covariances.” Econometric Reviews 11 (1992), 143-172.

4. Darrat, A., Elkhal K. and S. Hakim. "On the Integration of Emerging Stock Markets in the Middle East." Journal of Economic Development 25 (2000), 61-78.

5. Engle, R. F. and C.W.J. Granger. "Cointegration And Error Correction: Representation, Estimation And Testing." Econometrica 55 (1987), 251-276.

6. Erb, C., C. Harvey, and T. Viskanta. "Expected Returns and Volatility in 135 Countries." Journal of Portfolio Management (Spring) (1996), 46-58.

7. $\quad$ Forbes, K. and R. Rigobon. "Measuring Contagion: Conceptual And Empirical Issues." Stijn Claessens and Kristin Forbes, eds. International Financial Contagion, Boston, MA: Kluwer Academic Publishers, (2001), 43-66.

8. Girard, E. and T. Zaher. "Asymmetric Behavior of Stock Returns in MENA Capital Markets.” Review of Finance 2 (2002), 1-17.

9. $\quad$ Granger, Clive, B. Huang, and C.Yang. "A Bivariate Causality between Stock Prices and Exchange Rates: Evidence from Recent Asian Flu." The Quarterly Review of Economics and Finance 40 (2000), 337-354.

10. Harvey, C. "The Cross-Section of Volatility and Autocorrelation in Emerging Markets." Finanzmarkt und Portfolio Management 9 (1995a), 12-34.

11. Harvey, C. "The Risk Exposure of Emerging Equity Markets." World Bank Economic Review (1995b), 19-50.

12. Harvey, C. "Predictable Risk and Returns in Emerging Markets." Review of Financial Studies (1995c), 773-816.

13. Johansen, S. "Statistical Analysis of Cointegration Vectors." Journal of Economic Dynamics and Control 12 (1988), 231-54.

14. Liew, J. "Stock Returns, Inflation and the Volatility of Growth in the Money Supply: Evidence from Emerging Markets." University of Chicago, Working Paper Series (1995).

15. Omran M., and L. Gündüz. "Stochastic Trends and Stock Prices in Emerging Markets: The Case of Middle East and North Africa Region." Istanbul Stock Exchange Review 5 (2001), 3-16.

16. Osterwald-Lenum, M. "A Note with Quintiles of the Asymptotic Distribution of the Maximum Likelihood Cointegration Rank Test Statistics.” Oxford Bulletin of Economics and Statistics 54 (1992), 461-472.

17. Pesaran, H.M. and Y. Shin. "Generalized Impulse Response Analysis in Linear Multivariate Models." Economics Letters 58 (1998), 17-29. 
Table 1

Data Source, Starting Date, And Number Of Observations For Each Series

\begin{tabular}{|c|c|c|c|c|c|}
\hline $\begin{array}{c}\text { Country/ } \\
\text { Region }\end{array}$ & Source & $\begin{array}{c}\text { Coverage } \\
\text { (Start) }\end{array}$ & $\begin{array}{c}\text { Obs. } \\
\text { (Daily) }\end{array}$ & $\begin{array}{c}\text { Obs. } \\
\text { (Weekly) }\end{array}$ & $\begin{array}{c}\text { Obs. } \\
\text { (Monthly) }\end{array}$ \\
\hline Bahrain & IFC (US Dollar) & $4 / 19 / 00$ & 476 & 86 & 20 \\
\hline Egypt & MSCI (US Dollar) & $12 / 30 / 94$ & 1857 & 363 & 84 \\
\hline Israel & MSCI (US Dollar) & $1 / 1 / 93$ & 2378 & 467 & 108 \\
\hline Jordan & MSCI (US Dollar) & $1 / 1 / 90$ & 3161 & 624 & 144 \\
\hline Kuwait & KIC (local currency) & $12 / 28 / 94$ & 1859 & 363 & 84 \\
\hline Lebanon & BLOM (local currency) & $1 / 22 / 96$ & 1580 & 308 & 71 \\
\hline Morocco & MSCI (US Dollar) & $1 / 2 / 95$ & 1857 & 363 & 84 \\
\hline Oman & IFC (US Dollar) & $4 / 20 / 00$ & 476 & 86 & 20 \\
\hline Saudi Arabia & IFC (US Dollar) & $1 / 2 / 98$ & 1077 & 206 & 48 \\
\hline Tunisia & TUNINDEX (local currency) & $1 / 1 / 98$ & 1078 & 206 & 48 \\
\hline Turkey & MSCI (US Dollar) & $1 / 1 / 90$ & 3161 & 624 & 144 \\
\hline Asia ${ }^{2}$ & MSCI (US Dollar) “All Countries” & $1 / 1 / 90$ & 3161 & 624 & 144 \\
\hline Europe ${ }^{3}$ & MSCI (US Dollar) “All Countries” & $1 / 1 / 90$ & 3161 & 624 & 144 \\
\hline East Europe ${ }^{4}$ & MSCI (US Dollar) “All Countries” & $1 / 1 / 95$ & 1858 & 363 & 84 \\
\hline Latin America ${ }^{5}$ & MSCI (US Dollar) “All Countries” & $1 / 1 / 90$ & 3161 & 624 & 144 \\
\hline North America ${ }^{6}$ & MSCI (US Dollar) “All Countries” & $1 / 1 / 90$ & 3161 & 624 & 144 \\
\hline
\end{tabular}

${ }^{1}$ Indicates the data providers of daily index prices in U.S. Dollar. Local market series are converted into U.S. Dollars using the corresponding exchange rate series provided by Datastream.

2 All developed and emerging markets in the Asian MSCI universe.

3 All developed and emerging markets in the European MSCI universe.

4 Includes Russia and Poland.

5 All developed and emerging markets in the Latin American MSCI universe.

${ }^{6}$ Includes USA and Canada. 
Table 2

Augmented Dickey Fuller (ADF) Procedure Test Statistic Values

(Values for which we fail to reject the null hypothesis at least at the $5 \%$ level are highlighted) ${ }^{1}$

\begin{tabular}{|c|c|c|c|c|c|c|c|c|c|c|c|c|c|c|c|c|}
\hline \multirow[b]{3}{*}{ Country } & \multicolumn{4}{|c|}{ Daily } & \multicolumn{5}{|c|}{ Weekly } & \multicolumn{7}{|c|}{ Monthly } \\
\hline & \multicolumn{4}{|c|}{ Lag } & \multicolumn{5}{|c|}{ Lag } & \multicolumn{7}{|c|}{ Lag } \\
\hline & 1 & 2 & 4 & 10 & 1 & 2 & 3 & 4 & 10 & 1 & 2 & 3 & 4 & 6 & 8 & 10 \\
\hline Bahrain & -1.845 & -1.703 & -1.493 & -1.372 & -1.22 & -1.676 & -1.815 & -1.854 & -1.066 & NA & NA & NA & NA & NA & NA & NA \\
\hline Egypt & -0.267 & -0.292 & -0.32 & -0.339 & -0.263 & -0.33 & -0.391 & -0.41 & -0.547 & -0.434 & -0.524 & -0.507 & -0.411 & -0.504 & -0.338 & -0.291 \\
\hline Israel & -0.083 & -0.116 & -0.11 & -0.103 & -0.043 & -0.134 & -0.129 & -0.03 & -0.031 & -0.042 & 0.052 & 0.078 & -0.36 & 0.031 & -0.682 & -0.168 \\
\hline Jordan & -0.367 & -0.367 & -0.37 & -0.415 & -0.405 & -0.416 & -0.453 & -0.428 & -0.373 & -0.409 & -0.395 & -0.372 & -0.39 & -0.332 & -0.2 & -0.175 \\
\hline Kuwait & 0.831 & 0.865 & 0.907 & 0.82 & 0.872 & 0.745 & 0.608 & 0.567 & 0.438 & 0.503 & 0.4 & 0.392 & 0.242 & 0.17 & -0.012 & 0.015 \\
\hline Lebanon & -1.233 & -1.228 & -1.16 & -1.137 & -1.108 & -1.096 & -1.128 & -1.08 & -1.014 & -1.04 & -1.064 & -1.065 & -1.125 & -1.011 & -1.123 & -1.111 \\
\hline Morocco & 0.257 & 0.223 & 0.171 & 0.096 & 0.18 & 0.153 & 0.1 & 0.041 & -0.039 & 0.041 & 0.001 & -0.081 & -0.071 & -0.214 & -0.131 & -0.187 \\
\hline Oman & -1.846 & -1.913 & -1.448 & -1.332 & -1.455 & -1.299 & -1.388 & -1.33 & -0.948 & NA & NA & NA & NA & NA & NA & NA \\
\hline S. Arabia & 0.867 & 0.763 & 0.635 & 0.647 & 0.534 & 0.419 & 0.412 & 0.401 & 1.051 & 0.393 & 0.782 & 0.551 & 0.262 & 0.474 & 0.759 & 0.974 \\
\hline Tunisia & 0.019 & 0.039 & 0.128 & 0.089 & -0.113 & -0.189 & -0.214 & -0.167 & 0.054 & -0.13 & 0.015 & 0.132 & 0.355 & 0.297 & 0.146 & 0.232 \\
\hline Turkey & -1.182 & -1.205 & -1.176 & -1.38 & -1.13 & -1.286 & -1.404 & -1.285 & -1.222 & -1.327 & -1.337 & -1.287 & -1.305 & -1.285 & -1.217 & -1.179 \\
\hline Asia & -1.199 & -1.209 & -1.202 & -1.139 & -1.165 & -1.087 & -1.043 & -1.078 & -0.719 & -1.03 & -0.82 & -0.448 & -0.513 & -0.599 & -0.408 & -0.437 \\
\hline Europe & 0.643 & 0.734 & 0.726 & 0.85 & 1.014 & 1.005 & 0.919 & 1.017 & 1.043 & 1.053 & 1.132 & 1.06 & 1.081 & 0.909 & 0.684 & 0.161 \\
\hline East Europe & -0.845 & -0.845 & -0.896 & -0.852 & -0.874 & -0.823 & -0.757 & -0.601 & -0.489 & -0.584 & -0.595 & -0.481 & -0.544 & -0.48 & -0.516 & -0.49 \\
\hline North America & 1.151 & 1.207 & 1.313 & 1.511 & 1.669 & 1.618 & 1.549 & 1.724 & 1.944 & 1.73 & 1.888 & 1.71 & 1.562 & 1.247 & 1.149 & 0.105 \\
\hline Latin America & 0.106 & 0.137 & 0.104 & 0.074 & 0.249 & 0.094 & 0.06 & -0.001 & 0.093 & 0.095 & 0.117 & 0.107 & 0.214 & 0.354 & 0.124 & 0.021 \\
\hline
\end{tabular}

1 Augmented Dickey Fuller (ADF) procedure tests for Ho: $\phi=1$ in $\Delta x_{t}=\alpha+\beta t+(\phi-1) x_{t-1}+\sum_{i=1}^{k-1} \theta_{i} \Delta x_{t-i}+\varepsilon_{t}$, where $\Delta=1-L, x_{t}$ is the index level, $\varepsilon_{t}$ is white noise, $\alpha$ is the intercept, $\beta t$ is a trend component; the series is said to be stationary if the null hypothesis is rejected; critical values for rejection of hypothesis of trend stationary are, for 1 lag, -1.62 (10\% level), -1.95 ( $5 \%$ level) and -2.59 ( $1 \%$ level). 
Table 3

Kwiatkowski, Philips, Smith And Shin (KPSS) Procedure Test Statistic Values

(Values for which we fail to reject the null hypothesis at least at the $5 \%$ level are highlighted) ${ }^{1}$

\begin{tabular}{|c|c|c|c|c|c|c|c|c|c|c|c|c|c|c|c|c|}
\hline \multirow[b]{3}{*}{ Country } & \multicolumn{4}{|c|}{ Daily } & \multicolumn{5}{|c|}{ Weekly } & \multicolumn{7}{|c|}{ Monthly } \\
\hline & \multicolumn{4}{|c|}{ Lag } & \multicolumn{5}{|c|}{ Lag } & \multicolumn{7}{|c|}{ Lag } \\
\hline & 1 & 2 & 4 & 10 & 1 & 2 & 3 & 4 & 10 & 1 & 2 & 3 & 4 & 6 & 8 & 10 \\
\hline Bahrain & 13.794 & 9.234 & 5.584 & 2.601 & 2.825 & 1.928 & 1.48 & 1.211 & 0.621 & NA & NA & NA & NA & NA & NA & NA \\
\hline Egypt & 19.427 & 12.964 & 7.793 & 3.563 & 3.958 & 2.654 & 2.002 & 1.611 & 0.762 & 0.978 & 0.675 & 0.526 & 0.439 & 0.341 & 0.291 & 0.263 \\
\hline Israel & 62.469 & 41.682 & 25.049 & 11.435 & 12.598 & 8.433 & 6.349 & 5.098 & 2.371 & 2.908 & 1.98 & 1.512 & 1.23 & 0.913 & 0.739 & 0.633 \\
\hline Jordan & 30.745 & 20.506 & 12.315 & 5.613 & 6.166 & 4.122 & 3.1 & 2.486 & 1.15 & 1.438 & 0.971 & 0.738 & 0.598 & 0.438 & 0.35 & 0.295 \\
\hline Kuwait & 15.503 & 10.342 & 6.213 & 2.834 & 3.112 & 2.081 & 1.566 & 1.256 & 0.583 & 0.727 & 0.493 & 0.377 & 0.307 & 0.229 & 0.187 & 0.161 \\
\hline Lebanon & 52.226 & 34.849 & 20.946 & 9.569 & 10.505 & 7.038 & 5.304 & 4.262 & 1.992 & 2.423 & 1.657 & 1.273 & 1.042 & 0.777 & 0.629 & 0.535 \\
\hline Morocco & 40.147 & 26.78 & 16.086 & 7.336 & 8.085 & 5.408 & 4.069 & 3.265 & 1.513 & 1.975 & 1.338 & 1.018 & 0.826 & 0.607 & 0.487 & 0.412 \\
\hline Oman & 7.99 & 5.374 & 3.281 & 1.574 & 1.656 & 1.168 & 0.926 & 0.78 & 0.475 & NA & NA & NA & NA & NA & NA & NA \\
\hline S. Arabia & 30.896 & 20.62 & 12.398 & 5.672 & 6.258 & 4.198 & 3.167 & 2.548 & 1.199 & 1.397 & 0.956 & 0.735 & 0.604 & 0.458 & 0.382 & 0.338 \\
\hline Tunisia & 31.319 & 20.939 & 12.633 & 5.825 & 6.334 & 4.283 & 3.258 & 2.644 & 1.306 & 1.42 & 1.021 & 0.813 & 0.681 & 0.516 & 0.428 & 0.376 \\
\hline Turkey & 33.054 & 22.066 & 13.274 & 6.077 & 6.605 & 4.434 & 3.348 & 2.697 & 1.279 & 1.541 & 1.064 & 0.824 & 0.681 & 0.521 & 0.436 & 0.384 \\
\hline Asia & 10.559 & 7.05 & 4.241 & 1.942 & 2.112 & 1.419 & 1.072 & 0.863 & 0.408 & 0.474 & 0.328 & 0.255 & 0.21 & 0.159 & 0.132 & 0.116 \\
\hline Europe & 138.433 & 92.313 & 55.413 & 25.22 & 27.733 & 18.511 & 13.899 & 11.131 & 5.094 & 6.421 & 4.305 & 3.245 & 2.609 & 1.883 & 1.481 & 1.225 \\
\hline East Europe & 25.915 & 17.298 & 10.403 & 4.763 & 5.231 & 3.512 & 2.652 & 2.137 & 1.013 & 1.225 & 0.847 & 0.656 & 0.542 & 0.413 & 0.344 & 0.303 \\
\hline North America & 138.119 & 92.104 & 55.29 & 25.166 & 27.658 & 18.462 & 13.863 & 11.104 & 5.083 & 6.382 & 4.28 & 3.226 & 2.593 & 1.872 & 1.472 & 1.219 \\
\hline Latin America & 91.024 & 60.732 & 36.496 & 16.664 & 18.36 & 12.293 & 9.258 & 7.438 & 3.473 & 4.33 & 2.948 & 2.255 & 1.84 & 1.367 & 1.104 & 0.939 \\
\hline
\end{tabular}

1 Kwiatkowski, Phillips, Schmidt and Shin procedure tests for Ho: $d=0$ in $x_{t}=\alpha+\beta t+d \sum_{i=1}^{t} u_{i}+\varepsilon_{t}$ and $\mathrm{u}_{\mathrm{t}}=\mathrm{x}_{\mathrm{t}}-x_{t-1}, x_{t}$ is the index level, $\varepsilon_{t}$ and $u_{i}$ is white noise, $\alpha$ is the intercept, $\beta t$ is a trend component; the series is said to be "trend" stationary if the null hypothesis is accepted; critical values for KPSS tests are tabulated by Kwiatkowski, Phillips, Schmidt and Shin (1992): Kwiatkowski, Phillips, Schmidt and Shin critical values for rejection of hypothesis of trend stationary are 0.347 (10\% level), 0.463 (5\% level) and 0.739 (1\% level). 
Table 4

Intra-Regional Pairwise Bilateral Cointegration Statistical Test Values

(Values for which we reject the null hypothesis at least at $5 \%$ or $1 \%$ level are highlighted) ${ }^{1}$

\begin{tabular}{|c|c|c|c|c|c|c|c|c|c|c|c|}
\hline Country & Frequency & Bahrain & & & & & & & & & \\
\hline \multirow[t]{3}{*}{ Egypt } & Daily & $17.49(\mathrm{D}, 6)$ & & & & & & & & & \\
\hline & Weekly & 6.81(A,1) & & & & & & & & & \\
\hline & Monthly & $\mathrm{NC}$ & Egypt & & & & & & & & \\
\hline \multirow[t]{3}{*}{ Israel } & Daily & $8.76(\mathrm{~A}, 2)$ & $19.36(\mathrm{D}, 2)$ & & & & & & & & \\
\hline & Weekly & $10.72(\mathrm{E}, 6)$ & 4.93(A,6) & & & & & & & & \\
\hline & Monthly & $\mathrm{NC}$ & $18.01(\mathrm{D}, 1)$ & Israel & & & & & & & \\
\hline \multirow[t]{3}{*}{ Jordan } & Daily & $21.30 *[1](\mathrm{B}, 5)$ & $5.37(\mathrm{~A}, 1)$ & $25.92 *[1](\mathrm{D}, 10)$ & & & & & & & \\
\hline & Weekly & $20.21 *[1](\mathrm{B}, 2)$ & $5.51(\mathrm{~A}, 2)$ & $30.21 *(1)(\mathrm{D}, 5)$ & & & & & & & \\
\hline & Monthly & $\mathrm{NC}$ & $19.36(\mathrm{D}, 1)$ & 23.43(D,1) & Jordan & & & & & & \\
\hline \multirow[t]{3}{*}{ Kuwait } & Daily & $13.47(\mathrm{D}, 6)$ & $2.5(\mathrm{~A}, 1)$ & $2.28(\mathrm{~A}, 1)$ & $7.94(\mathrm{~A}, 1)$ & & & & & & \\
\hline & Weekly & $14.20(\mathrm{E}, 2)$ & $4.28(\mathrm{~A}, 3)$ & $2.78(\mathrm{~A}, 1)$ & $8.07(\mathrm{~A}, 1)$ & & & & & & \\
\hline & Monthly & $\mathrm{NC}$ & $8.21(\mathrm{~B}, 1)$ & $1.72(\mathrm{~A}, 1)$ & $5.20(\mathrm{~A}, 1) \mathrm{S}$ & Kuwait & & & & & \\
\hline \multirow[t]{3}{*}{ Lebanon } & Daily & $16.26(\mathrm{E}, 6)$ & 4.43(A,1) & $2.75(\mathrm{~A}, 1)$ & 7.12(A,1) & $20.51(\mathrm{D}, 4)$ & & & & & \\
\hline & Weekly & 7.54(A,1) & $4.45(\mathrm{~A}, 1)$ & $2.42(\mathrm{~A}, 1)$ & 7.23(A,1) & $23.19(\mathrm{D}, 1)$ & & & & & \\
\hline & Monthly & $\mathrm{NC}$ & $6.96(\mathrm{~B}, 1)$ & $2.17(\mathrm{~A}, 1)$ & $8.89(\mathrm{~A}, 1)$ & 8.20(A,1) & Lebanon & & & & \\
\hline \multirow[t]{3}{*}{ Morocco } & Daily & $21.76(\mathrm{D}, 9)$ & $3.45(\mathrm{E}, 3)$ & 5.42(E,5) & $8.47(\mathrm{E}, 3)$ & $18.20 * *[1](\mathrm{A}, 5)$ & $16.32 * *[1](\mathrm{E}, 1)$ & & & & \\
\hline & Weekly & $8.35(\mathrm{C}, 3)$ & $3.35(\mathrm{E}, 1)$ & $3.57(\mathrm{E}, 1)$ & $8.41(\mathrm{E}, 1)$ & $18.91 * *[1](\mathrm{A}, 1)$ & $12.64 *[1](\mathrm{A}, 1)$ & & & & \\
\hline & Monthly & $\mathrm{NC}$ & $5.31(\mathrm{~A}, 1)$ & $4.46(\mathrm{~A}, 1)$ & 13.61(E,1) & $16.59(\mathrm{~A}, 1)$ & $11.981(\mathrm{~A}, 1)$ & Morocco & & & \\
\hline \multirow[t]{3}{*}{ Oman } & Daily & 14.71(D,6) & $6.61(C, 1)$ & $9.73(\mathrm{~A}, 1)$ & $15.51(\mathrm{~B}, 1)$ & $15.29(\mathrm{~B}, 1)$ & $10.89(\mathrm{~A}, 1)$ & $6.54(\mathrm{C}, 1)$ & & & \\
\hline & Weekly & $12.80(\mathrm{E}, 2)$ & $\mathrm{NC}$ & $15.88(\mathrm{E}, 5)$ & $18.45(\mathrm{~B}, 1)$ & $\mathrm{NC}$ & $11.80(\mathrm{~A}, 1)$ & $\mathrm{NC}$ & & & \\
\hline & Monthly & $\mathrm{NC}$ & $\mathrm{NC}$ & $\mathrm{NC}$ & $\mathrm{NC}$ & $\mathrm{NC}$ & $\mathrm{NC}$ & $\mathrm{NC}$ & Oman & & \\
\hline \multirow[t]{3}{*}{ S. Arabia } & Daily & $19.31(\mathrm{D}, 5)$ & $1.71(\mathrm{~A}, 3)$ & $8.43(\mathrm{~A}, 1)$ & $11.93(\mathrm{~B}, 1)$ & $7.88(\mathrm{E}, 4)$ & 10.74(A,1)S & $26.98 *[1](\mathrm{D}, 3)$ & $8.87(\mathrm{~A}, 1)$ & & \\
\hline & Weekly & $16.71(\mathrm{D}, 1)$ & $2.09(\mathrm{~A}, 1)$ & $6.38(\mathrm{~A}, 1)$ & $13.83(\mathrm{~B}, 1)$ & 7.49(E,8) & $25.12(\mathrm{D}, 5)$ & $26.15 *[1](\mathrm{A}, 1)$ & $\mathrm{NC}$ & & \\
\hline & Monthly & $\mathrm{NC}$ & $\mathrm{NC}$ & $\mathrm{NC}$ & NC & $\mathrm{NC}$ & $\mathrm{NC}$ & $\mathrm{NC}$ & $\mathrm{NC}$ & S. Arabia & \\
\hline \multirow[t]{3}{*}{ Turkey } & Daily & $9.28(\mathrm{C}, 1) \mathrm{S}$ & $13.87 *[1](\mathrm{A}, 7)$ & $30.73 * *[1](\mathrm{B}, 13)$ & $17.00(\mathrm{~B}, 19)$ & $4.26(\mathrm{~A}, 10)$ & $4.01(\mathrm{~A}, 1) \mathrm{S}$ & $5.23(\mathrm{~A}, 1) \mathrm{S}$ & 7.02(C,1)S & $3.65(\mathrm{~A}, 3)$ & \\
\hline & Weekly & 7.18(E,3) & 16.92(E,2) & $16.69 * *[1](\mathrm{A}, 7)$ & $18.57(\mathrm{~B}, 3)$ & $3.72(\mathrm{~A}, 1)$ & $3.77(\mathrm{~A}, 1)$ & $3.923(\mathrm{~A}, 1)$ & $\mathrm{NC}$ & $2.66(\mathrm{~A}, 1)$ & \\
\hline & Monthly & $\mathrm{NC}$ & $8.50(\mathrm{~A}, 1)$ & $22.28 *[1](\mathrm{E}, 5)$ & $17.43(\mathrm{~B}, 1)$ & $2.94(\mathrm{~A}, 1)$ & $2.76(\mathrm{~A}, 1)$ & $6.476(\mathrm{~A}, 1)$ & $\mathrm{NC}$ & $\mathrm{NC}$ & Turkey \\
\hline \multirow[t]{3}{*}{ Tunisia } & Daily & $11.18(\mathrm{C}, 1)$ & $16.3(\mathrm{D}, 3)$ & $13.45(\mathrm{~B}, 2)$ & $18.56(\mathrm{D}, 1)$ & 12.44(E,1) & 7.11(A,1) & $25.35 *[1](\mathrm{D}, 3)$ & $7(\mathrm{~A}, 1)$ & $13.29(\mathrm{~B}, 1)$ & $2.58(\mathrm{~A}, 1) \mathrm{S}$ \\
\hline & Weekly & $16.44(\mathrm{E}, 5)$ & $19.25(\mathrm{D}, 2)$ & $13.23(\mathrm{~B}, 1)$ & $4.41(\mathrm{~A}, 3)$ & $12.01(\mathrm{E}, 1)$ & $15.34(\mathrm{C}, 3)$ & $27.35 *[1](\mathrm{A}, 4)$ & $\mathrm{NC}$ & $11.83(\mathrm{~B}, 1)$ & $19.78(\mathrm{D}, 2)$ \\
\hline & Monthly & $\mathrm{NC}$ & $\mathrm{NC}$ & $\mathrm{NC}$ & $\mathrm{NC}$ & $\mathrm{NC}$ & NC & NC & $\mathrm{NC}$ & $\mathrm{NC}$ & $\mathrm{NC}$ \\
\hline
\end{tabular}

Log likelihood ratio are first reported, critical values are tabulated by Osterwald-Lenum (1992); * (**) denotes rejection of the null hypothesis at 5\% (1\%) significant level; the number of cointegration equations are in brackets. When convergence with either the AIC, SIC and BIC cannot be achieved, we report "NC" (no convergence). Optimal model and lag are found with the Akaike Info Criterion ("S" indicates that we cannot find a minimum with the AIC, in that case we use the Schwartz Info Criterion); the optimal model and lag number are indicated, respectively, by letter and number in each parenthesis. Thus, when letter A is used for model reference, it is assumed no deterministic trend in the data, and no intercept or trend in the cointegrating equation. If B is used, indicates no deterministic trend in the data, and an intercept but no trend in the cointegrating equation. If $\mathrm{C}$, it indicates linear trend in the data, and an intercept but no trend in the cointegrating equation. If $\mathrm{D}$, it indicates linear trend in the data, and both an intercept and a trend in the cointegrating equation. If $\mathrm{E}$, it indicates a quadratic trend in the data, and both an intercept and a trend in the cointegrating equation. 
Table 5

Inter-regional Pairwise Bilateral Cointegration Statistical Test Values

(Values for which we reject the null hypothesis at least at $5 \%$ or $1 \%$ level are highlighted) ${ }^{1}$

\begin{tabular}{|c|c|c|c|c|c|c|c|c|c|c|c|c|}
\hline Country & Frequency & Bahrain & Egypt & Israel & Jordan & Kuwait & Lebanon & Morocco & Oman & Saudi Arabia & Turkey & Tunisia \\
\hline \multirow[t]{3}{*}{ Asia } & Daily & $11.85(\mathrm{C}, 1)$ & $4.37(\mathrm{~A}, 1)$ & $20.19(\mathrm{D}, 13)$ & $12.81 *[1](\mathrm{A}, 6)$ & $17.66(\mathrm{~B}, 1)$ & $3.73(\mathrm{~A}, 1)$ & $7.36(\mathrm{E}, 1)$ & $18.28(\mathrm{D}, 1)$ & $9.06(\mathrm{~A}, 3)$ & $9.31(\mathrm{~A}, 1) \mathrm{S}$ & $15.4(\mathrm{D}, 1)$ \\
\hline & Weekly & $\mathrm{NC}$ & 4.15(A,3) & $3.08(\mathrm{~A}, 1)$ & $12.91 *[1](\mathrm{A}, 1)$ & $19.16(\mathrm{~B}, 1)$ & $19.60(\mathrm{D}, 1)$ & $5.71(\mathrm{E}, 1)$ & $\mathrm{NC}$ & $14.83(\mathrm{E}, 2)$ & $6.66(\mathrm{~A}, 14)$ & $17.79(\mathrm{E}, 2)$ \\
\hline & Monthly & $\mathrm{NC}$ & 4.56(A, 1$)$ & $19.45(\mathrm{D}, 1)$ & $9.63(\mathrm{~B}, 4)$ & $8.20(\mathrm{~A}, 1)$ & 3.73(A,1) & $2.55(\mathrm{~A}, 1)$ & $\mathrm{NC}$ & $\mathrm{NC}$ & 7.56(A,3) & $\mathrm{NC}$ \\
\hline \multirow[t]{3}{*}{ Europe } & Daily & $9.62(\mathrm{~A}, 10)$ & $6.02(\mathrm{~A}, 1)$ & $14.6(\mathrm{~B}, 1)$ & $5.69(\mathrm{~A}, 7)$ & $18.53(\mathrm{D}, 7)$ & $6.05(\mathrm{~A}, 1)$ & $7.26(\mathrm{E}, 7)$ & 9.72(A,1) & $14.92(\mathrm{~B}, 2)$ & $8.87(\mathrm{~A}, 2) \mathrm{S}$ & $18.65 *[1](\mathrm{E}, 2)$ \\
\hline & Weekly & $\mathrm{NC}$ & $10.46(\mathrm{~A}, 7)$ & $15.75(\mathrm{~B}, 1)$ & $4.46(\mathrm{~A}, 3)$ & $19.70(\mathrm{D}, 2)$ & $6.81(\mathrm{~A}, 1)$ & $7.20(\mathrm{E}, 1)$ & $\mathrm{NC}$ & $18.87(\mathrm{D}, 1)$ & $10.98(\mathrm{~A}, 3)$ & $24.31 * *[1](\mathrm{E}, 2)$ \\
\hline & Monthly & $\mathrm{NC}$ & 11.17(A,1) & $15.75(\mathrm{~B}, 2)$ & $18.43(\mathrm{D}, 1)$ & $17.08(\mathrm{~B}, 1)$ & 7.49(A, 1$)$ & $19.71(\mathrm{~B}, 1)$ & $\mathrm{NC}$ & $\mathrm{NC}$ & 10.714(A,1) & $\mathrm{NC}$ \\
\hline \multirow[t]{3}{*}{ E. Europe } & Daily & $14.06(\mathrm{C}, 1)$ & $4.73(\mathrm{~A}, 10)$ & $3.34(\mathrm{~A}, 13)$ & $6.62(\mathrm{~A}, 1)$ & $16.85^{* *}[1](\mathrm{A}, 10)$ & $22.89(\mathrm{D}, 1)$ & $26.43 * *[1](\mathrm{B}, 1)$ & $15.27(\mathrm{D}, 1)$ & $22.75(\mathrm{D}, 10)$ & $4.23(\mathrm{~A}, 10)$ & $19.37(\mathrm{D}, 13)$ \\
\hline & Weekly & $\mathrm{NC}$ & $4.22(\mathrm{~A}, 3)$ & $2.41(\mathrm{~A}, 5)$ & $7.24(\mathrm{~A}, 2)$ & $16.13 *[1](\mathrm{A}, 2)$ & $6.41(\mathrm{~A}, 1)$ & $20.38 *[1](\mathrm{B}, 2)$ & $\mathrm{NC}$ & $20.90(\mathrm{D}, 2)$ & $3.32(\mathrm{~A}, 4)$ & $6.549(\mathrm{~A}, 2)$ \\
\hline & Monthly & $\mathrm{NC}$ & $3.45(\mathrm{~A}, 1)$ & $2.31(\mathrm{~A}, 1)$ & $19.41(\mathrm{D}, 1)$ & $12.98 *[1](\mathrm{A}, 1)$ & $\mathrm{NC}$ & $15.92(\mathrm{~B}, 1)$ & $\mathrm{NC}$ & $\mathrm{NC}$ & $3.13(\mathrm{~A}, 1)$ & $\mathrm{NC}$ \\
\hline \multirow[t]{3}{*}{ L. America } & Daily & $10.1(\mathrm{C}, 1) \mathrm{S}$ & $18.5(\mathrm{~B}, 10)$ & $3.15(\mathrm{~A}, 7)$ & $7.54(\mathrm{~A}, 6)$ & $19.32(\mathrm{D}, 12)$ & $20.84(\mathrm{D}, 1)$ & $4.76(\mathrm{~A}, 10)$ & $8.86(\mathrm{~A}, 1)$ & $6.25(\mathrm{~A}, 2)$ & 6.24(A,1)S & $15.76(\mathrm{~B}, 1)$ \\
\hline & Weekly & $\mathrm{NC}$ & $17.35(\mathrm{~B}, 2)$ & $3.64(\mathrm{~A}, 2)$ & $6.40(\mathrm{~A}, 3)$ & $18.51(\mathrm{D}, 2)$ & $3.29(\mathrm{~A}, 1)$ & $6.37(\mathrm{E}, 1)$ & $\mathrm{NC}$ & $4.74(\mathrm{~A}, 1)$ & $7.23(\mathrm{~A}, 2)$ & 21.64(D,1) \\
\hline & Monthly & $\mathrm{NC}$ & $17.71(\mathrm{~B}, 1)$ & $2.79(\mathrm{~A}, 1)$ & $6.39(\mathrm{~A}, 1)$ & $16.67(\mathrm{D}, 1)$ & 2.59(A, 1) & $4.72(\mathrm{~B}, 1)$ & $\mathrm{NC}$ & $\mathrm{NC}$ & 7.48(A,1) & $\mathrm{NC}$ \\
\hline \multirow[t]{3}{*}{ N. America } & Daily & $11.68(\mathrm{C}, 1)$ & $5.78(\mathrm{~A}, 3)$ & $20.42 *[1](\mathrm{B}, 15)$ & $5.45(\mathrm{~A}, 15)$ & $13.4(\mathrm{D}, 4)$ & $5.98(\mathrm{~A}, 1)$ & $20.85 *[1](\mathrm{B}, 3)$ & $6.04(\mathrm{C}, 2)$ & $21.94 *[1](\mathrm{B}, 3)$ & $8.57(\mathrm{~A}, 1) \mathrm{S}$ & $12.93 *[1](\mathrm{B}, 2)$ \\
\hline & Weekly & $\mathrm{NC}$ & 6.90(A, 1) & $23.43^{*}[1](\mathrm{B}, 6)$ & $5.29(\mathrm{~A}, 1)$ & $14.94(\mathrm{D}, 2)$ & $6.36(\mathrm{~A}, 1)$ & $20.36 *[1](\mathrm{B}, 1)$ & $\mathrm{NC}$ & $20.62 *[1](\mathrm{B}, 1)$ & $9.11(\mathrm{C}, 3)$ & $18.66 *[1](\mathrm{E}, 2)$ \\
\hline & Monthly & $\mathrm{NC}$ & $10.20(\mathrm{~A}, 1)$ & $24.62 * *[1](\mathrm{C}, 8)$ & $6.86(\mathrm{C}, 1)$ & $8.71(\mathrm{C}, 1)$ & $\mathrm{NC}$ & $25.98 * *[1](\mathrm{B}, 1)$ & $\mathrm{NC}$ & $\mathrm{NC}$ & $12.26(\mathrm{~A}, 1)$ & $\mathrm{NC}$ \\
\hline
\end{tabular}

Log likelihood ratio are first reported, critical values are tabulated by Osterwald-Lenum (1992); * (**) denotes rejection of the null hypothesis at 5\% (1\%) significant level; the number of cointegration equations are in brackets. When convergence with either the AIC, SIC and BIC cannot be achieved, we report "NC" (no convergence). Optimal model and lag are found with the Akaike Info Criterion ("S" indicates that we cannot find a minimum with the AIC, in that case we use the Schwartz Info Criterion); the optimal model and lag number are indicated, respectively, by letter and number in each parenthesis. Thus, when letter $\mathrm{A}$ is used for model reference, it is assumed no deterministic trend in the data, and no intercept or trend in the cointegrating equation. If B is used, indicates no deterministic trend in the data, and an intercept but no trend in the cointegrating equation. If $\mathrm{C}$, it indicates linear trend in the data, and an intercept but no trend in the cointegrating equation. If $\mathrm{D}$, it indicates linear trend in the data, and both an intercept and a trend in the cointegrating equation. If $\mathrm{E}$, it indicates a quadratic trend in the data, and both an intercept and a trend in the cointegrating equation. 